\title{
Variation in Senescence Pattern of Different Classes of Rice Tillers and Its Effect on Panicle Biomass Growth and Grain Yield
}

\author{
Ekamber Kariali, Sunita Sarangi, Rashmi Panigrahi, Binay B. Panda, Pravat K. Mohapatra* \\ School of Life Sciences, Sambalpur University, Sambalpur, India. \\ Email: *pravat1948@rediffmail.com
}

Received April 30 $0^{\text {th }}, 2012$; revised May 27 $7^{\text {th }}, 2012$; accepted June $8^{\text {th }}, 2012$

\begin{abstract}
In rice, the initiation of tillers is staggered and temporally spaced, but maturity is synchronous. Duration of growth in a later-initiated tiller on a higher culm node is shorter and it contributes less biomass and grain yield. The present investigation attempts to discover the manner in which ordered pattern of senescence in basipetal succession impacts source capacity of tillers in two contrasting rice cultivars, namely Lalat (high tillering) and MGD-106 (medium tillering) during the dry season of 2009 and ascertain how tiller production capacity influences dry matter partitioning and tiller dynamics of the plant. In both the rice cultivars, the progress of senescence among different types of tillers was indicated by gradual decline of photosynthetic pigments, total nitrogen and protein concentrations and increase of lipid peroxidation and peroxidase activity of the flag leaf, which affected photosynthetic efficiency. The effects were more pernicious on the newer tillers compared to older tillers. It was observed that metabolic dominance of the older tillers over newer tillers could be accrued due to higher photosynthetic source capacity of the former than that of the latter. It was concluded that flag leaf of a later-initiated tiller is less tolerant to senescence induced photo-oxidative stress, which decreases both source and sink activities. Increase of tiller number and order in rice increases vulnerability of the later-initiated tillers for oxidative stress and grain filling.
\end{abstract}

Keywords: Rice; Tiller; Senescence; Photosynthetic Efficiency

\section{Introduction}

Monsoonal rains primarily sustain rice cultivation in the tropics and semi tropics during wet season. The rainfall pattern is often uneven and uncertain. Erratic rains invite environmental stresses like flooding, drought and low irradiance. For survival rice plant adopts reproductive strategies, such as production of many more tillers than that are taken to maturity. The plant sacrifices some tillers to salvage the residual units for completion of life cycle when incidence of environmental stresses limit primary production. Because the order of tiller development is asynchronous [1], poorly developed organs are the preferred targets for environmental decimation. Similarly under stress free situation tillers produced beyond resource capacity are corrected by senescence. Among the tillers, the pattern of panicle development is hierarchical and grain yield becomes poorer in each successive tiller [2]. Usually panicles of the late-formed tillers on higher nodes do not contribute to grain yield [3]. A high yielding semi dwarf rice plant produces a large number of

${ }^{*}$ Corresponding author. tillers, one in each successive leaf axil at different time intervals; the initiation and development of the tillers are staggered and temporally spaced, but maturation is synchronous [4]. Therefore, a late-formed tiller on a higher culm node senesces earlier than that of an older tiller and contributes less in grain number and yield. Although genetic potential does not restrict tiller development, premature senescence of the newer tillers limits grain yield by reduction of effective panicle number of the plant [5] and number of grains on the newer tillers. As of today, the physiological mechanism that limits production capacity of tillers and suppresses biomass production and grain yield potential of rice is poorly understood. Besides we know very little about the impact of tiller production capacity on management of biomass distribution between plant parts.

As envisaged hitherto, grain number per panicle is a plastic yield component; the spatial location of the tiller determines panicle grain number. Conversely, the other components like effective tiller number and grain weight are under genetic control [6,7]. Therefore, regulation of tiller dynamics is important for crop management; too 
few tillers limit grain yield and too many tillers result high tiller abortion, poor grain filling and reduction of panicle size [8]. It is said that a tiller of rice plant is a specialized grain bearing branch, which grows independently of the main shoot by means of its adventitious roots [9]. But, the manner, in which an ordered pattern of senescence in basipetal succession impacts source capacity for grain filling and thereby determines grain yield in each tiller is not known. Similarly, the physiological advantages enjoyed by an older tiller over that of a relatively new tiller for grain filling and the bias against development of the latter are unclear. In this study, it was desired to compare the senescence pattern of the photosynthetic tissues of the main shoot, primary and secondary tillers during the period of reproductive development. In the process, we investigated the role played by senescence in the regulation of source capacity for grain filling and physiological competence of each class of tiller for metabolic dominance. Metabolic dominance of a tiller could be indicative of its capacity for survival.

\section{Materials and Methods}

\subsection{Plant Material and Experimental Site}

Seeds of two contrasting tiller producing rice (Oryza sativa L.) namely Lalat, high tillering type (Obs 677/ IR2071//Vikram/W1263) and MGD-106 (Teqing/Binam //Teqing///Teqing) a medium tillering Indica $X$ japonica hybrid were obtained from Dr. S. R. Das, Professor and Rice Breeder, Odisha University of Agriculture and Technology, Bhubaneswar and grown in cemented pots $(53 \times 53 \times 33 \mathrm{~cm})$ containing $42 \mathrm{Kg}$ of sandy loam soil mixed with farm yard manure (3:1) under open field condition in the Botanical garden of the School of Life Sciences, Sambalpur University, India (latitude $21.29^{\circ} \mathrm{N}$, longitude $84^{\circ} \mathrm{E}$, altitude $178 \mathrm{~m}$ ) during the dry season of 2009. The seedlings were grown in a nursery bed and transplanted to the experimental pots 30 days after germination. The pots were arranged in a complete randomized block design and all observations were made in three replicates on each occasion of sampling. The plants were given commercial fertilizers consisting of $\mathrm{N}, \mathrm{P}_{2} \mathrm{O}_{5}$ and $\mathrm{K}_{2} \mathrm{O}$ at the rate of 80:40:40 in split doses. The plants were irrigated with water as and when required and the water level of the pots was maintained $5 \pm 2 \mathrm{~cm}$ for all the time except a few days after transplantation and before maturity.

Uniformly grown plants were screened and different categories of tillers in these plants were tagged from the stage of tiller emergence. The tags were periodically checked to ensure identity. Tillers developed from the leaf axil of un-extended part of the stem during the vegetative period. Each node of the main shoot had one tiller except that of the coleoptile and first leaf nodes. The tillers borne on the leaf axils of the main shoot were called primary tillers. Similarly tillers borne on the axils of primary tillers were named secondary tillers and those on the secondary tillers were tertiary tillers. Tiller formation occurred in a definite order; emergence of the fifth leaf of the culm coincided with that of the first leaf of the tiller of the second leaf; thus, the $n$th leaf of the culm and first leaf of the tiller on the $n-3$ node of the culm grew simultaneously. Emergence of tillers coincided with formation of fibrous roots from the node.

\subsection{Morphological Observations and Sampling}

Various observations were made from the tiller representatives like the main shoot (M), first primary tiller (P), first secondary tiller of the first primary tiller (S) and first tertiary tiller $(\mathrm{T})$ that emerged from the first secondary tiller of $P$. The height and leaf area of the tillers were measured weekly from the date of tiller emergence to maturity [5]. The height was measured from the base to the tip of the uppermost leave/panicle whereas the leaf area of a tiller was determined by the product of length and maximum width of leaf multiplied by a factor of 0.69 [5]. The date of panicle initiation, booting, $50 \%$ anthesis and maturity of the tillers were recorded carefully. Photosynthetic efficiency of the plants $(\mathrm{Fv} / \mathrm{Fm})$ in the flag leaves of the tillers were measured weekly from booting to maturity by the help of Handy PEA (model no. RS 232, serial no. 2320, Hansatech, UK). These measurements were done in the morning between $9.00-10.00 \mathrm{AM}$ with saturating light levels exceeding $1500 \mu \mathrm{mol} \cdot \mathrm{m}^{-2} \cdot \mathrm{s}^{-1}$. The panicles of the tiller representatives were harvested at maturity for the determination of panicle length, dry weight, number of filled and unfilled grains, and number of primary branches, total grain weight and 1000 grain weight.

\subsection{Biochemical Assays}

The photosynthetic pigments and protein concentrations of the flag leaf of different tillers were assayed during booting, anthesis and maturity. Flag leaves of tillers were cut from the base of the leaf lamina and sized into small pieces before grinding in a glass mortar and pestle with pre-chilled $80 \%$ acetone. The concentration of the photosynthetic pigments was determined according to the procedure of Arnon [10]. The residue after the extraction of the pigments was dissolved in $10 \%$ TCA. The slurry was centrifuged to discard the supernatant. The residue was dissolved in $1 \mathrm{~N} \mathrm{NaOH}$ and aliquot of this extract was used for the determination of protein concentration as per the method described by Lowry et al. [11]. Similarly, lipid peroxidation in terms of malondialdehyde 
(MDA) contents [12], peroxidase enzyme activity [13] and nitrogen contents [14] of the flag leaves of different tillers were measured on the occasions of booting, anthesis and maturity.

\subsection{Statistical Analysis}

Experimental data for plant height, leaf area and PS-II efficiency $(\mathrm{Fv} / \mathrm{Fm})$ of the tillers on different sampling occasions of the cultivars were analysed by ANOVA (Analysis of variance) in Microsoft excel computer program (double factor ANOVA without replication). However, data for other biochemical assays and yield parameters were analysed by Duncan's multiple range test (DMRT), Crop Stat.7.2.

\section{Results}

\subsection{Panicle Grain Yield}

Both Lalat and MGD-106 rice cultivars produced a number of tillers; the number was higher in the former than the latter (Table 1). Tertiary tiller production was absent in MGD-106 cultivar. Among the classes of tillers, the values for length, dry mass, spikelet number, percentage of filled grains and average grain weight of the panicle were high in the main shoot (Table 1). The features declined progressively from the main shoot through primary tiller to secondary or tertiary tillers in both the cultivars. Conversely barren spikelet number of the panicle showed an opposite trend. The late-formed tillers contributed poorly to the grain yield of the plant. Com- pared to Lalat, panicle size and grain yield of different types of tillers of MGD-106 cultivar were lower. Moreover, variation in grain yield among the classes of tillers was higher in the high-tillering Lalat than that of the medium-tillering MGD-106 cultivar. The total number of tillers was higher in Lalat than that of MGD-106. Similarly, total weight, length, grain weight, spikelet number and percentage of filled grains of the panicle of the tillers were higher in Lalat compared to the corresponding class of tiller of MGD-106. In contrast, average grain weight of the tillers was higher in MGD-106 than that of Lalat.

\subsection{Tiller Height and Leaf Area}

Similar to grain yield, the height of tiller was high in the main shoot and it declined temporally among the laterformed tillers (Figure 1). Tiller height increased progressively with time until 3 - 4 weeks before maturity. MGD-106 tillers were considerably taller than that of Lalat. Flag leaf area increased until six weeks after tillering in both the rice cultivars and declined thereafter. The leaf area was larger in an older tiller compared to a newer all through the period of investigation. The height and flag leaf area of the different classes of tillers changed significantly with passage of time in both the cultivars as well.

\subsection{Fv/Fm Ratio of the Flag Leaf}

The maximum quantum efficiency of PS II of the flag leaf, measured as Fv/Fm ratio, did not differ significantly

Table 1. Morphological features of the panicles of individual tillers of two indica rice cultivars Lalat and MGD-106. Total number of tillers at maturity in Lalat, $29.0 \pm 1.732$ and MGD-106, $12.667 \pm 1.528$. The \pm values represent SD of three replicates. M, Mother; P, Primary; S, Secondary; T, Tertiary.

\begin{tabular}{|c|c|c|c|c|c|c|c|c|c|c|c|c|}
\hline \multirow{2}{*}{$\begin{array}{l}\text { Name of } \\
\text { rice } \\
\text { cultivar }\end{array}$} & \multirow{2}{*}{$\begin{array}{c}\text { Name of } \\
\text { tiller }\end{array}$} & \multirow{2}{*}{$\begin{array}{c}\text { Panicle } \\
\text { length }(\mathrm{cm})\end{array}$} & \multirow{2}{*}{$\begin{array}{c}\text { Panicle } \\
\text { weight (g) }\end{array}$} & \multirow{2}{*}{$\begin{array}{c}\text { No. of } \\
\text { primary } \\
\text { branches }\end{array}$} & \multirow{2}{*}{$\begin{array}{l}\text { No. of } \\
\text { spikelets/ } \\
\text { panicle }\end{array}$} & \multirow{2}{*}{$\begin{array}{l}\text { No. of } \\
\text { filled } \\
\text { grains/ } \\
\text { panicle }\end{array}$} & \multirow{2}{*}{$\begin{array}{c}\text { No of } \\
\text { unfilled } \\
\text { grains/ } \\
\text { panicle }\end{array}$} & \multicolumn{2}{|c|}{ Percentage of } & \multirow{2}{*}{$\begin{array}{c}\text { Total } \\
\text { filled } \\
\text { grain } \\
\text { weight }(\mathrm{g})\end{array}$} & \multirow{2}{*}{$\begin{array}{c}\text { Total } \\
\text { unfilled } \\
\text { grain } \\
\text { weight }(\mathrm{g})\end{array}$} & \multirow{2}{*}{$\begin{array}{c}1000 \\
\text { grain } \\
\text { weight }(\mathrm{g})\end{array}$} \\
\hline & & & & & & & & $\begin{array}{l}\text { filled } \\
\text { grains }\end{array}$ & $\begin{array}{c}\text { unfilled } \\
\text { grains }\end{array}$ & & & \\
\hline \multirow{8}{*}{ Lalat } & \multirow{2}{*}{ M } & 28.26 & 3.82 & 12.4 & 171.00 & 162.66 & 08.75 & 95.13 & 4.87 & 3.48 & 0.035 & 21.86 \\
\hline & & $\mathrm{a}$ & $\mathrm{a}$ & $\mathrm{a}$ & $\mathrm{a}$ & $\mathrm{a}$ & $\mathrm{e}$ & $\mathrm{a}$ & $\mathrm{d}$ & $\mathrm{a}$ & $\mathrm{b}$ & $\mathrm{b}$ \\
\hline & \multirow{2}{*}{$\mathrm{P}$} & 26.26 & 3.39 & 12.2 & 168.66 & 157.00 & 11.66 & 93.08 & 6.91 & 3.21 & 0.058 & 20.81 \\
\hline & & $\mathrm{b}$ & $\mathrm{a}$ & $\mathrm{a}$ & $\mathrm{a}$ & $\mathrm{a}$ & $\mathrm{e}$ & $\mathrm{a}$ & $\mathrm{d}$ & $\mathrm{a}$ & b & $\mathrm{b}$ \\
\hline & \multirow{2}{*}{$\mathrm{S}$} & 26.12 & 2.26 & 12.0 & 164.00 & 145.12 & 18.21 & 88.42 & 11.57 & 2.9 & 0.107 & 20.66 \\
\hline & & $\mathrm{b}$ & $\mathrm{b}$ & $\mathrm{a}$ & $\mathrm{a}$ & $\mathrm{b}$ & $\mathrm{d}$ & $\mathrm{b}$ & $\mathrm{d}$ & $\mathrm{a}$ & $\mathrm{b}$ & $\mathrm{b}$ \\
\hline & \multirow{2}{*}{$\mathrm{T}$} & 21.66 & 1.83 & 08.66 & 90.33 & 067.23 & 26.00 & 74.18 & 25.82 & 1.46 & 0.142 & 18.53 \\
\hline & & $\mathrm{c}$ & $\mathrm{b}$ & $\mathrm{b}$ & $\mathrm{c}$ & d & $\mathrm{d}$ & $\mathrm{c}$ & $\mathrm{c}$ & $\mathrm{c}$ & $\mathrm{b}$ & $\mathrm{b}$ \\
\hline \multirow{6}{*}{ MGD-106 } & \multirow{2}{*}{ M } & 19.75 & 2.98 & 11.5 & 135.33 & 083.15 & 52.33 & 61.26 & 38.73 & 2.28 & 0.302 & 25.46 \\
\hline & & $\mathrm{d}$ & $\mathrm{a}$ & $\mathrm{a}$ & $\mathrm{b}$ & $\mathrm{c}$ & $\mathrm{c}$ & d & b & b & $\mathrm{a}$ & $\mathrm{a}$ \\
\hline & \multirow[b]{2}{*}{ ] } & 19.00 & 2.19 & 09.66 & 134.33 & 073.75 & 61.12 & 54.59 & 45.41 & 2.11 & 0.363 & 24.13 \\
\hline & & $\mathrm{e}$ & $\mathrm{b}$ & $\mathrm{b}$ & $\mathrm{b}$ & $\mathrm{c}$ & $\mathrm{b}$ & $\mathrm{e}$ & b & $\mathrm{b}$ & $\mathrm{a}$ & $\mathrm{a}$ \\
\hline & \multirow{2}{*}{$\mathrm{S}$} & 17.37 & 1.87 & 09.2 & 128.33 & 046.82 & 87.26 & 32.24 & 67.76 & 1.34 & 0.475 & 22.26 \\
\hline & & $\mathrm{f}$ & $\mathrm{b}$ & $\mathrm{b}$ & $\mathrm{b}$ & $\mathrm{e}$ & $\mathrm{a}$ & f & $\mathrm{a}$ & $\mathrm{c}$ & $\mathrm{a}$ & $\mathrm{a}$ \\
\hline \multicolumn{2}{|c|}{$\operatorname{LSD}(5 \%)$} & 0.647 & 1.104 & 1.713 & 22.041 & 14.8 & 7.841 & 3.422 & 13.83 & 0.789 & 0.194 & 3.355 \\
\hline
\end{tabular}

Means followed by common letters within a column shows no significant difference in Duncan's multiple range test (DMRT). 


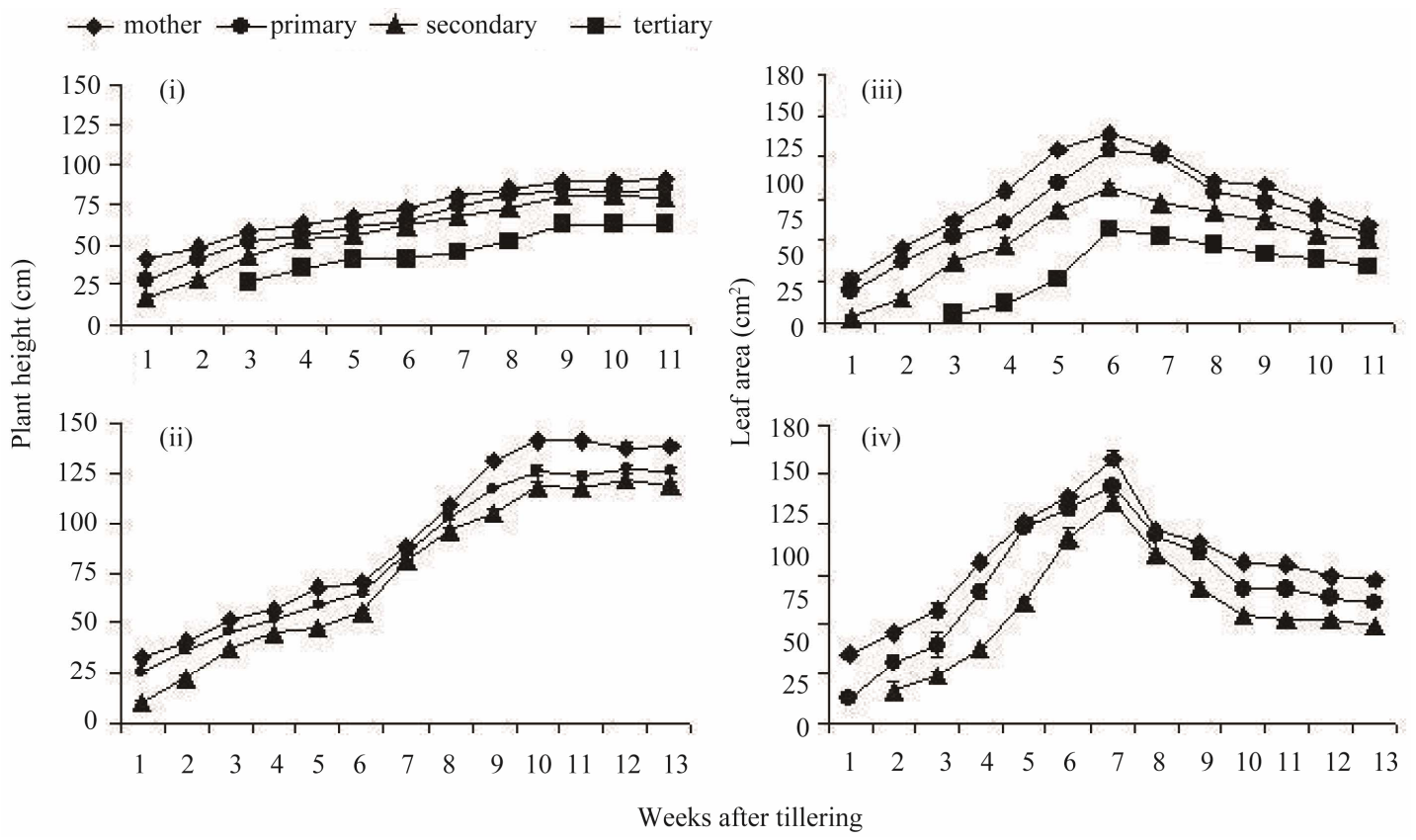

Figure 1. Plant height ((i) and (ii)) and leaf area ((iii) and (iv)) of different types of tillers of high tillering Lalat (top) and medium tillering MGD-106 (bottom) rice cultivars. Data represented are the means of three replicates. The $F$ values between tillers and sampling occasions respectively, were as follows (i) $\left\{158.23 * * *\right.$ and $\left.120.857 * * *\left(\mathbf{n}_{1}=3 ; \mathbf{n}_{2}=10\right)\right\}$; (ii) $\{97.129 * * *$ and $\left.456.673 * * *\left(n_{1}=2 ; n_{2}=12\right)\right\}$; (iii) $\left\{78.566 * * *\right.$ and $\left.36.985 * * *\left(n_{1}=3 ; n_{2}=10\right)\right\} ;$ (iv) $\left\{77.664 * * *\right.$ and 81.345*** $\left.\left(\mathbf{n}_{1}=2 ; \mathbf{n}_{2}=12\right)\right\}$. Data analysis was done by ANOVA (Analysis of variance) in Microsoft Excel computer program (double factor ANOVA without replication). $* * * \mathbf{P} \geq \mathbf{0 . 0 0 1}$.

between the classes of tillers in Lalat $\left(\mathrm{F}=0.789^{\mathrm{NS}}\right)$, but showed significant difference in MGD-106 $\left(\mathrm{F}=11.971^{* *}\right)$ during the period between booting and maturity (Figure 2). However, on most of the sampling occasions, the ratio was higher in the flag leaf of the main shoot and primary tiller compared to that of the later-initiated tillers. With passage of time, the $\mathrm{Fv} / \mathrm{Fm}$ ratio declined marginally in all tillers. It indicated the temporal fall in primary photochemistry of the flag leaf of tillers.

\subsection{Photosynthetic Pigment Concentration of Flag Leaf}

The total chlorophyll concentration of the flag leaf was high in the main shoot. It declined progressively among the classes of the later-initiated tillers in both the rice cultivars (Figures 3(i) and (ii)). In comparison to Lalat, the total chlorophyll concentration did not vary as much between the tillers of MGD-106. Chlorophyll concentration of flag leaf changed significantly with passage of time. At the booting stage chlorophyll concentration of the flag leaf was low; it peaked at anthesis and declined thereafter till maturity in all tillers. However, for the later-initiated secondary and tertiary tillers, the decline in concentration between anthesis and maturity was not as sharp as that the early-initiated tillers. Carotenoid concentrations of the flag leaf of the different classes of till- ers exhibited fluctuation similar to that of the total chlorophylls (Figures 3(iii) and (iv)).

\subsection{Proteins and Nitrogen Concentration of the Flag Leaf}

Similar to the total chlorophylls concentration, the protein concentration of the flag leaf was low at booting stage; it peaked at anthesis and declined up to the maturity stage thereafter (Figures 4(i) and (ii)). However, unlike the total chlorophylls, the protein concentration did not differ as much between the classes of tillers, but differed significantly between different sampling occasions. The total nitrogen concentration of the flag leaf was high at the booting stage; it declined marginally at anthesis and drastically thereafter at maturity in all tillers of both the rice cultivars (Figures 4(iii) and (iv)). The flag leaf of the newer classes of tillers possessed lower concentration of nitrogen compared to the older tillers, but the differences were often not significant.

\subsection{Lipid Peroxidation and Peroxidase Activity of the Flag Leaf}

Lipid peroxidation, estimated as concentration of malonedi-aldehyde (MDA) and peroxidase activity increased temporally in the flag leaf; it was low at booting stage 


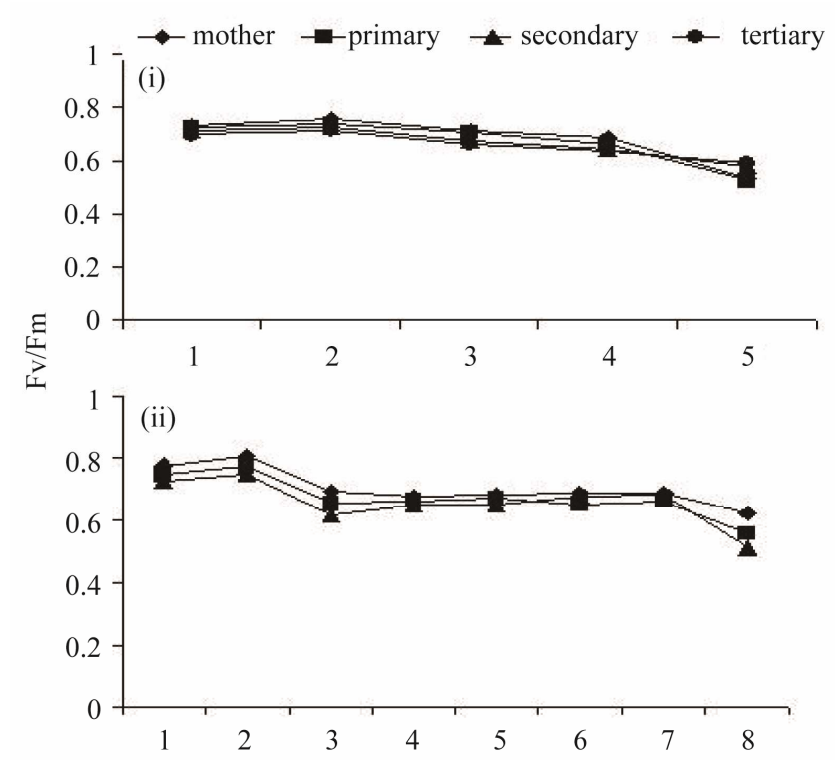

Figure 2. Photosystem II efficiency (Fv/Fm) of the flag leaves of different types of tillers from booting to maturity in high tillering Lalat (top) and medium tillering MGD-106(bottom) rice cultivars. Data represented are the means of three replicates. The $F$ values between tillers and sampling occasions respectively, were as follows. (i) $\left\{0.789^{\mathrm{NS}} ; 35.507 * * *\left(\mathrm{n}_{1}=3 ; \mathrm{n}_{2}=4\right)\right\}$ and (ii) $\left\{11.971 * ; 34.738 * * *\left(n_{1}=2 ; n_{2}=7\right)\right\}$. Data analysis was done by ANOVA (Analysis of variance) in Microsoft excel computer program (double factor ANOVA without replication). $* * P \geq 0.01, * * * P \geq 0.001$.
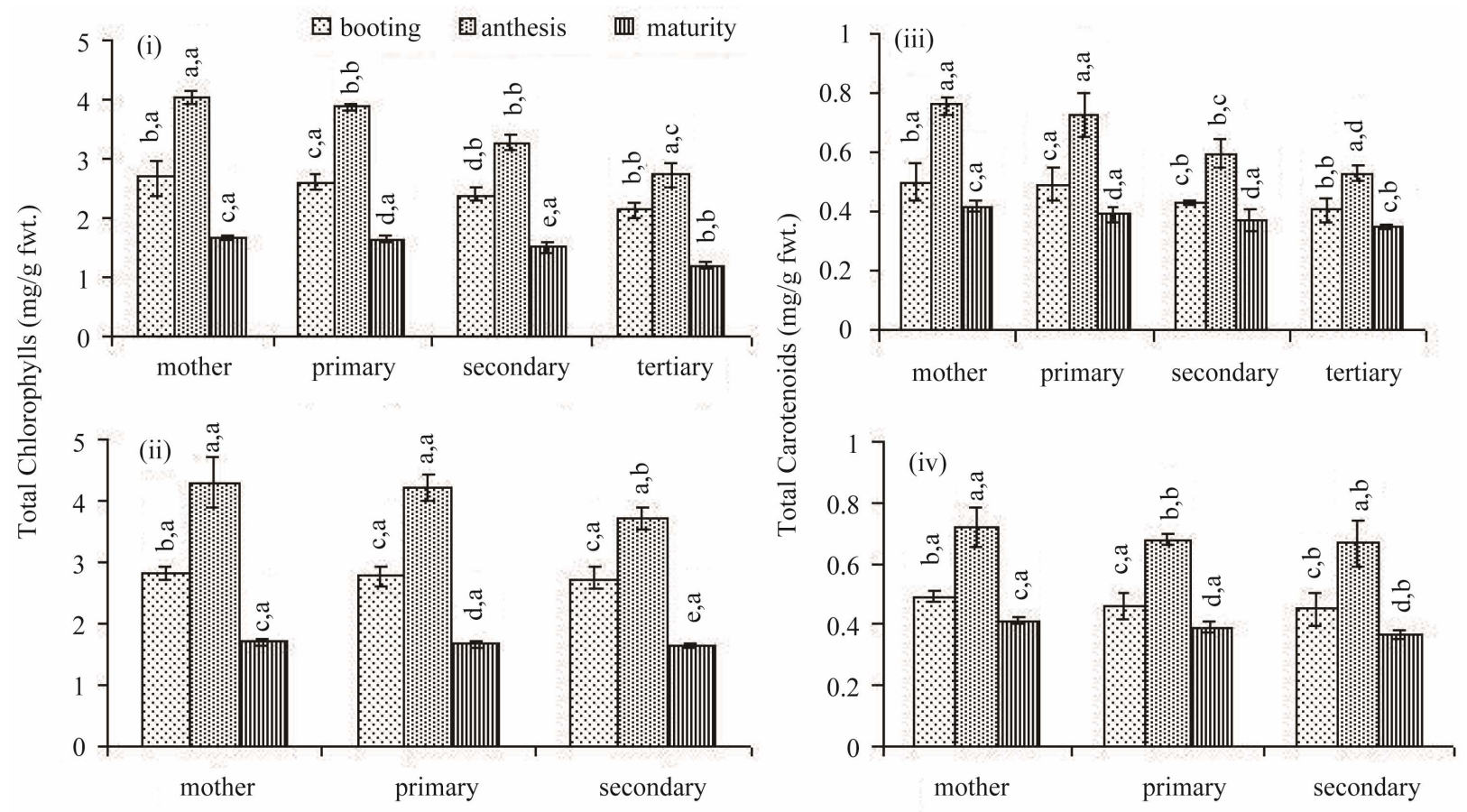

Type of tiller

Figure 3. Total chlorophylls ((i) and (ii)) and carotenoids ((iii) and (iv)) concentrations in the flag leaf of different types of tillers of high tillering Lalat (top) and medium tillering MGD-106 (bottom) rice cultivars at booting, anthesis and maturity. Data represented are the means of three replicates. Small letters above the vertical bars lower ones: $\mathbf{v} x \mathbf{d s} \times \mathbf{r}$, interaction between varieties ( $v$ ), ds (developmental stages) and $r$ (replicates) and upper ones " $v x t x$ " interaction between varieties ( $v$ ), $t$ (tillers) and replicates (r) $\}$. Common letters with "v $x$ ds $x$ " $(C V=0.769, L S D=0.294$ at $P \geq 0.05)$ and "v $x \mathrm{t} \times \mathrm{r}$ " (CV $=0.905$, $L S D=0.387$ at $P \geq 0.05)$ for (i) and (ii), and " $v \times$ ds $x$ " $(C V=0.029, L S D=0.044$ at $P \geq 0.05) ; \&$ "v $x$ t $x$ r" $(C V=0.126, L S D=$ 0.051 at $P \geq 0.05$ ) for (iii) and (iv) indicate no significant difference according to the Duncan's multiple range test (DMRT). 

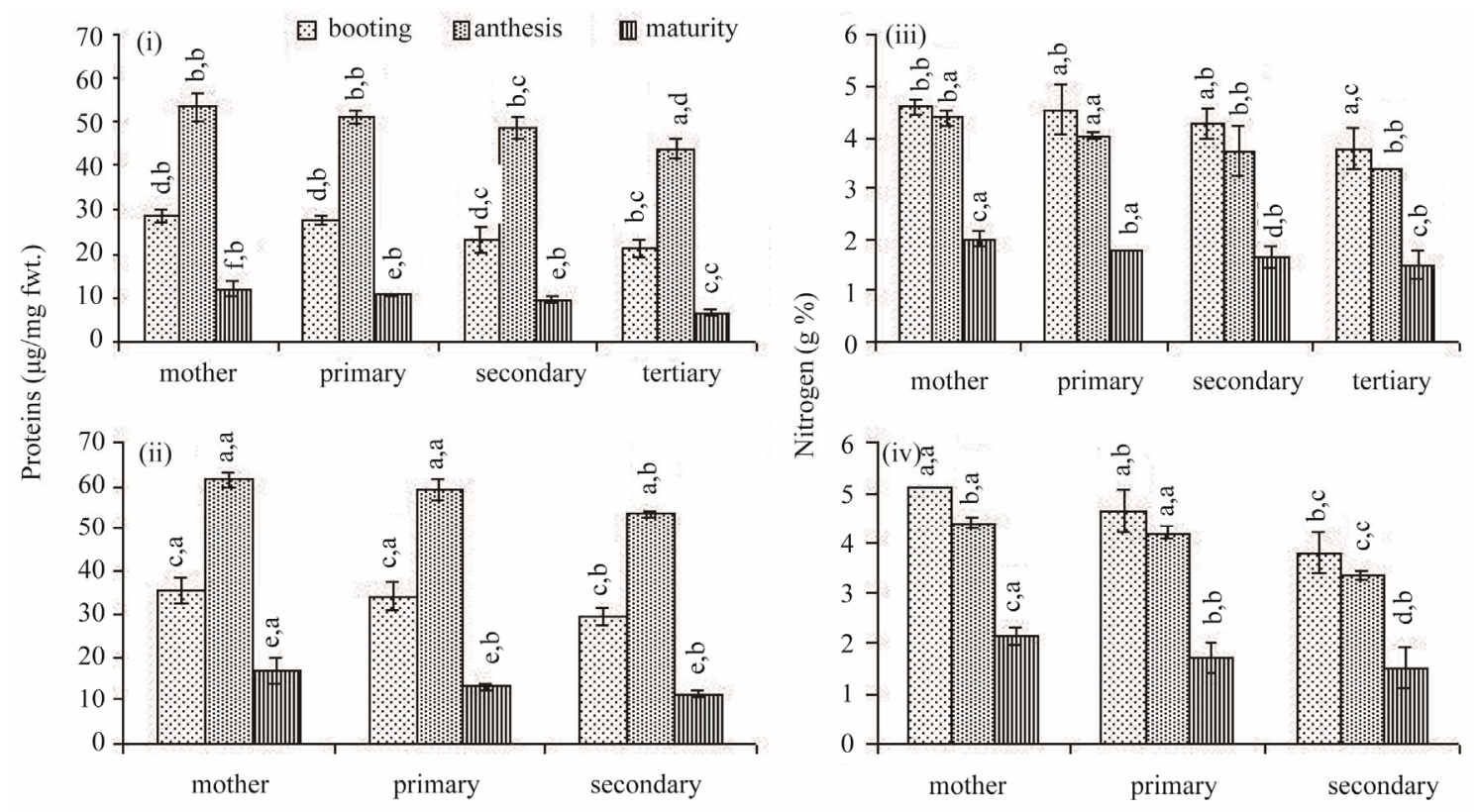

Type of tiller

Figure 4. Proteins ((i) and (ii)) and Nitrogen ((iii) and (iv)) concentrations in the flag leaf of different types of tillers of high tillering Lalat (top) and medium tillering MGD-106 (bottom) rice cultivars at booting, anthesis and maturity. Data represented are the means of three replicates. Small letters above the vertical bars \{lower ones: $\mathbf{v} x \mathbf{d s} \times \mathbf{r}$, interaction between varieties ( $v$ ), ds (developmental stages) and $r$ (replicates) and upper ones " $v \times t$ x $r$ " interaction between varieties (v), $t$ (tillers) and replicates (r) $)$. Common letters with " $\mathrm{v}$ ds $x \mathrm{r}$ " $(\mathrm{CV}=\mathbf{0 . 6 2 8}, \mathrm{LSD}=3.213$ at $\mathrm{P} \geq 0.05) \&$ "v $x \mathrm{t} \times \mathrm{r}$ " $(\mathrm{CV}=0.736, \mathrm{LSD}=$ 3.71 at $P \geq 0.05)$ for (i) and (ii) and " $v \times d s \times r "(C V=0.081, L S D=0.335$ at $P \geq 0.05)$; \& "v $x$ t $x$ r" $(C V=0.905, L S D=0.387$ at $P \geq 0.05$ ) for (iii) and (iv) indicate no significant difference according to the Duncan's multiple range test (DMRT).

and reached peak level at maturity in both the rice cultivars (Figures 5(i) and (ii)). MDA concentration of flag leaf did not exhibit much difference between the classes of tillers at similar stages of development. However, the peroxidase activity was higher in the later-initiated tillers compared to the older tillers (Figures 5(iii) and (iv)).

\subsection{Fluorescence (OJIP) Curve of the Flag Leaf}

The area above the fluorescence curve between Fo and Fm (OJIP curve), which gives an estimate of the electron acceptors on the reducing side of PS II, varied consistently between the tillers of both the rice cultivars, when measured at booting, anthesis and maturity stages of the flag leaf (Figure 6). At the booting and anthesis stages, the flag leaf exhibited greater efficiency of electron transfer in the main shoot than that of the later-initiated tillers, and the variation in efficiency was greater between the tillers of Lalat than that of MGD-106. But, the efficiency of the flag leaf on main shoot declined drasticcally at the maturity stage and became much lower than that of the flag leaf of secondary or tertiary tillers.

\section{Discussion}

The results described herewith revealed the hierarchical pattern of dominance between the different classes of tillers of rice plant. The main shoot bound more dry mass and produced well-developed flag leaf and panicle. Grain yield contribution of the panicle of main shoot was the highest among the tillers and yield of the successive tillers declined in a sequence [4]. Poor filling of spikelets in the panicle of the later-formed tillers was quite evident (Table 1). Poor filling might have contributed to the decline in grain quality of the later-initiated tillers as well. It is known that they were lower in panicle dry weight, chalky rice rate and amylose and protein contents [3]. In this study, the order of dominance among the tillers increased in a basipetal fashion. The asynchronous nature of the system influenced grain yield components and panicle grain number was more affected than that of the grain weight. It was opined that the weight of grain is fixed and cannot be manipulated beyond the genetic limitation [5]. Similarly, tiller asynchrony also influenced growth of the vegetative parts of the rice cultivars in a hierarchical pattern. Tiller height and flag leaf area decreased in an acropetal fashion from the base upwards (Figure 1). Florent et al. [15] reported variation in leaf blade dimension between classes of rice tillers and our study corroborated this observation. The later-initiated tillers like secondary or tertiary tillers possessed low 

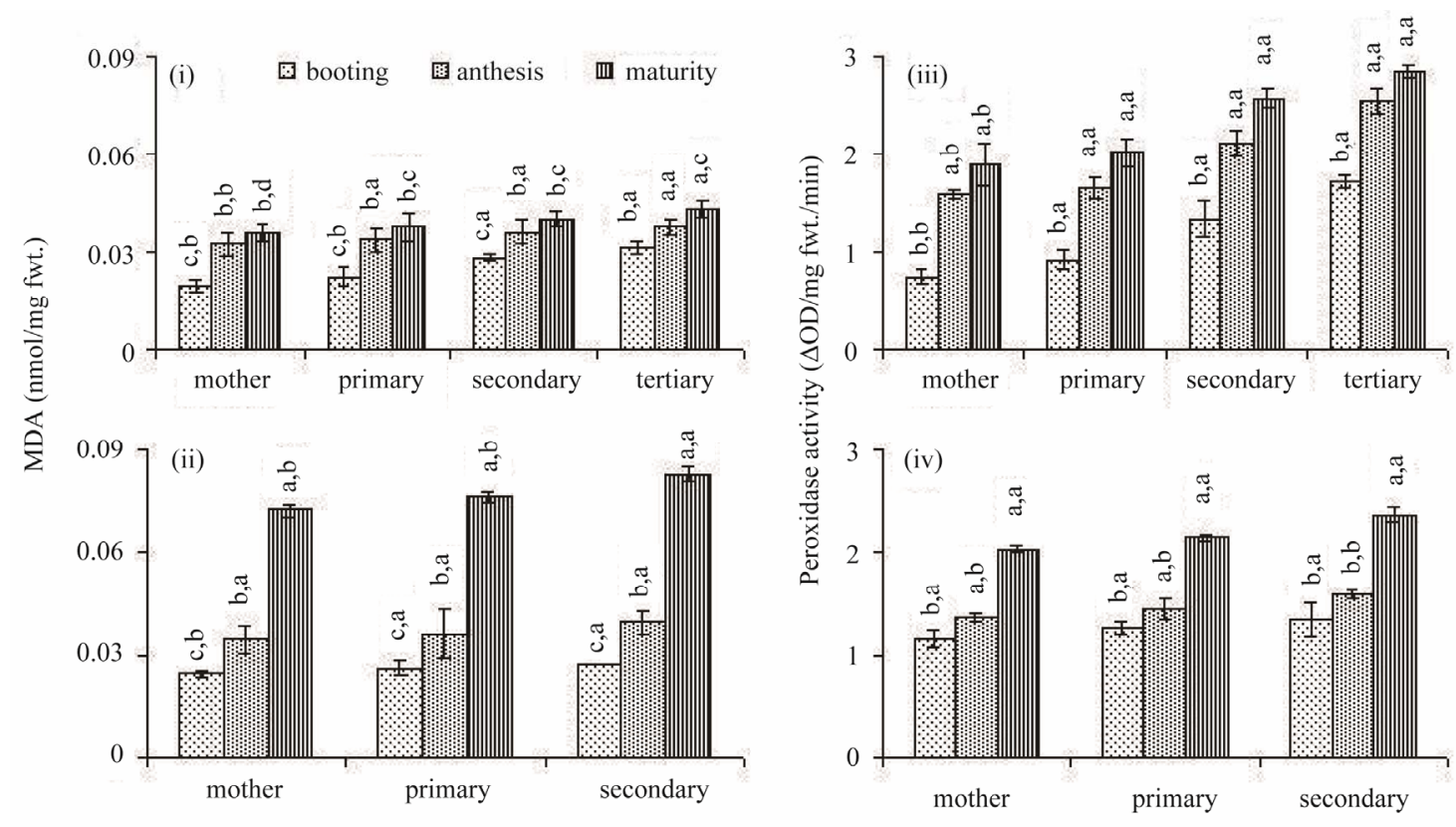

Type of tiller

Figure 5. Lipid peroxidations ((i) and (ii)) and peroxidase activity ((iii) and (iv)) in the flag leaf of different types of tillers of high tillering Lalat (top) and medium tillering MGD-106 (bottom) rice cultivars at booting, anthesis and maturity. Data represented are the means of three replicates. Small letters above the vertical bars (lower ones: $v \times d s \times r$, interaction between varieties (v), ds (developmental stages) and $r$ (replicates) and upper ones " $v$ x $t \times$ r" interaction between varieties (v), $t$ (tillers) and replicates (r) $\}$. Common letters with "v $x$ ds $x$ " $(C V=0.005, L S D=0.329$ at $P \geq 0.05) \&$ "v $x$ t $x$ r" (CV $=0.234$, LSD $=$ 0.006 at $P \geq 0.05)$ for (i) and (ii) and " $v \times d s \times r$ " $(C V=0.556, L S D=0.774$ at $P \geq 0.05)$; \& "v $x$ t $x$ " $(C V=0.578, L S D=$ 0.894 at $P \geq 0.05$ ) for (iii) and (iv) indicate no significant difference in the Duncan's multiple range test (DMRT).

source area to sustain adequate provision of assimilates for grain filling in both the cultivars. However, the variation among the classes of tillers in either source or sink capacities was higher in the high-tillering Lalat than that of the medium-tillering MGD-106 cultivar.

Metabolic dominance of the older tillers in the rice plant in this study could be accrued to the difference in provision of assimilates among the classes of tillers. The primary tillers possessed larger number of vascular bundles compared to the tertiary tillers and poor vascularisation in the latter restricted supply of assimilates and hormones for grain development in the reproductive parts [16]. Also the source activity for grain filling might have declined because of premature senescence of the leaf. Dingkuhn and Kropff [17] suggested that tiller number of rice is dynamic and resource dependent and tillering beyond a sustainable number is corrected by senescence. In rice plant, flag leaf is metabolically most active during grain formation [18] and provides maximum carbon assimilates to the growing panicle [19]. Therefore, we estimated tiller senescence by recording the progress of the event in the flag leaf of each class of tillers in the present study. Kariali and Mohapatra [20] found an ethylene mediated signal responsible for induction of senescence in the later-initiated tillers of rice. The same proposition was supported by Mohapatra et al. [21] in wild rice Oryza rufipogon. Environmental parameters like nutrient supply, plant density and irradiance control growth and development of emergent rice tillers [5,22], because of their effect on primary production. In both the rice cultivars studied in the present experiment, grain filling was poor in the recently-formed tillers because of premature senescence of the source leaf (Figures 3-5). Additionally, flag leaf area was small in the recently-formed tillers (Figure 1). In rice tiller initiation occurs in a temporal sequence, but the event of maturity is identical for all tillers [2]. Thus, the recently-formed tillers had shorter duration of growth and development compared to the older tillers in the present study. Reduction of source area might have depleted the assimilate provision for the panicle and limited grain yield of a newer tiller compared to an older tiller [2]. Further, the sequential pattern of tiller senescence was explicit from the degradation of the photosynthetic pigments and proteins (Figures 3, 4), decrease of total nitrogen concentration (Figure 4) and increase in activity of peroxidase enzyme and lipid peroxidation (Figure 5) in the flag leaf. The measure of these activities gave a quantitative estimate of leaf senescence [2]. Masle [23] reported that in winter wheat senescence begins with the most recently emerged tiller 

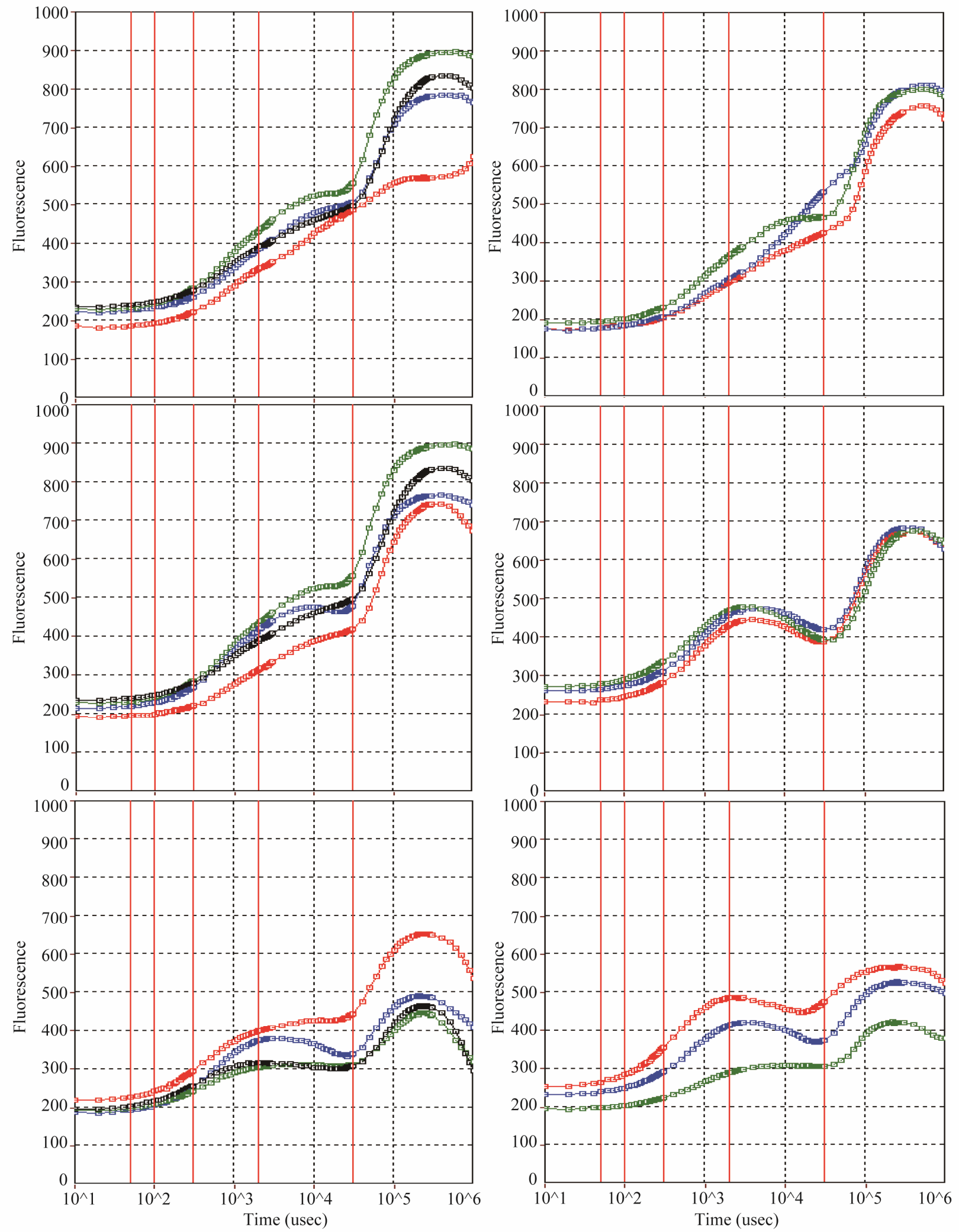

Figure 6. Fluorescence (O-J-I-P) curves of Mother (red), Primary (blue), Secondary (green) and Tertiary (black) tillers of high tillering Lalat (left) and medium-tillering MGD-106 (right) rice cultivar at booting (top), anthesis (middle) and maturity (bottom). 
(i)

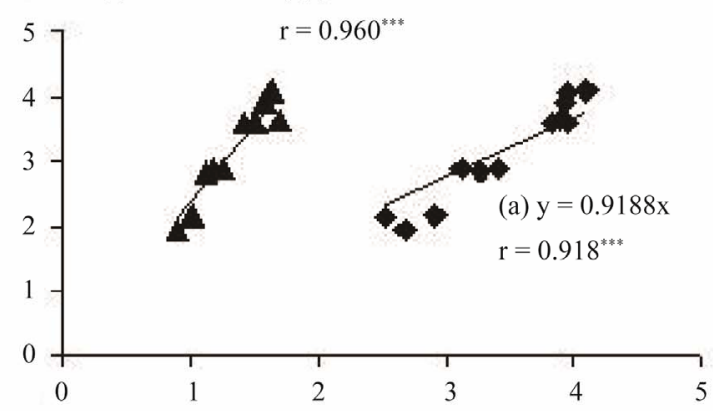

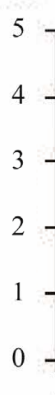

(ii)

(b) $y=2.5881 x-1.5431$ (a) $y=0.6957 x$ $\mathrm{r}=0.609^{\mathrm{NS}}$

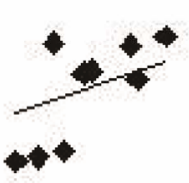

Total Chl. (mg/g fwt.)

(iii) (b) $\mathrm{y}=0.3148 \mathrm{x}+0.0817$ $\mathrm{r}=0.917^{* * *}$

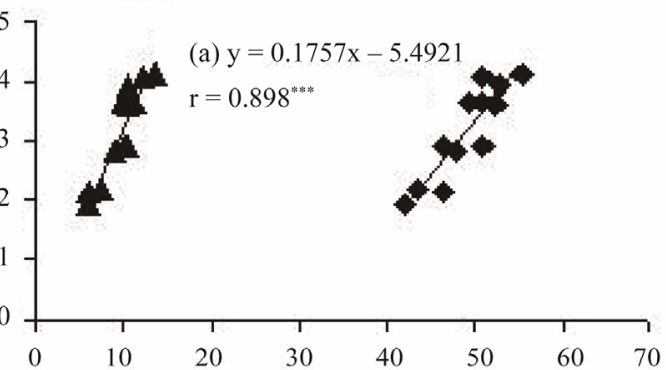

(iv)

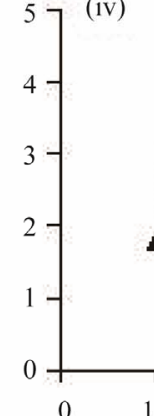

(b) $\mathrm{y}=0.1837 \mathrm{x}+0.2731$

$$
\mathrm{r}=0.699^{*}
$$

(a) $\mathrm{y}=0.1894 \mathrm{x}-8.1939$ $\mathrm{r}=0.916^{* * *}$

Protein ( $\mu \mathrm{g} / \mathrm{mg}$ fwt.)
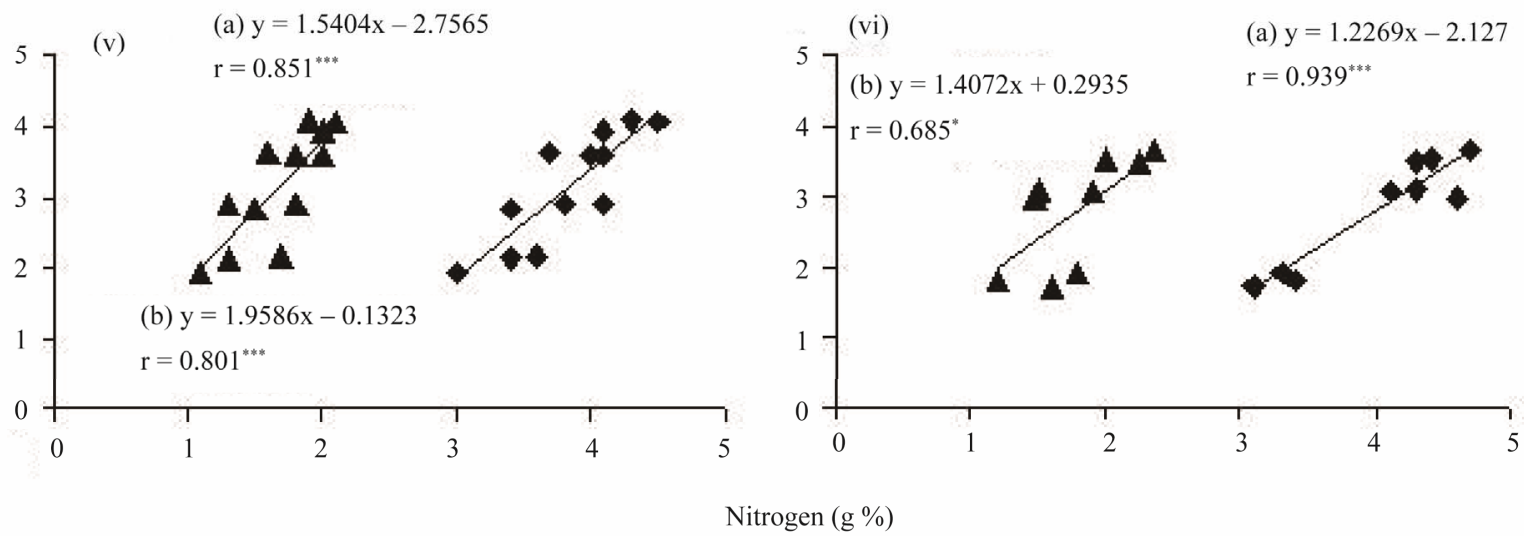

Figure 7. Correlations between total chlorophyll concentrations of flag leaf and panicle dry weight at maturity (top), protein concentrations of flag leaf and panicle dry weight at maturity (middle) and nitrogen concentrations of the flag leaf and panicle dry weight at maturity (bottom) in different types of tillers of high tillering Lalat (left) and medium tillering MGD-106 (right) rice cultivars. $\{n=12$ (4 tillers $\times 3$ replicates) for Lalat and 9 (3 tillers $\times 3$ replicates) for MGD-106\}.

and proceeds towards the preceding groups of tillers in the order of their age and slackening of growth spreads progressively from the youngest to the oldest tiller in sequence to their initiation time and eventually to the main stem. Our study with rice plant, however, suggested that coincidence of senescence among the classes of tillers might be responsible for building a smaller leaf area in a recently-formed tiller (Figure 1), which in turn could limit primary production in the source leaf to the detriment of grain filling of the panicle. The flag leaf of the secondary/tertiary tillers possessed lower concentrations of photosynthetic pigments and proteins, and lost them more quickly than that of the older tillers (Figures 3, 4). Evans and De Datta [24] reported that responsiveness of rice cultivars to irradiance is high under high nitrogen level. Hence, decline in leaf nitrogen concentration (Figure 4) with progress of senescence might have restricted primary production of assimilates in the present 
study. Ciompi et al. [25] found that nitrogen stress affected $\mathrm{CO}_{2}$ uptake, possibly through reduction in Rubisco activity, but the stress had no bearing on efficiency of PS II. Thus, low nitrogen level could be the immediate cause for premature senescence of a relatively new tiller. It is believed that rice plant possesses excess photosynthetic capacity to fulfill demand of growing organs in exigencies $[5,26,27]$. Therefore, it may be apt to suggest that retardation of growth in young tillers could be more related to lack of the sink activity than that of source activity. Premature senescence can put restriction of source area and supply of assimilates to the reproductive parts in young tillers.

Beltrano et al. [28] observed that early maturation shortens the grain filling period and reduces average grain weight in wheat. In our study, early maturity of the secondary/tertiary tillers resulted poor accumulation of dry mass in both vegetative and reproductive parts of the tillers (Table 1). Primary photochemistry of the flag leaf (Figure 2) was higher in the early-initiated tillers compared to that of the later-initiated tillers. Delay in emergence from the enclosure of the preceding leaf sheath could have extended exposure to intrinsic ethylene for the later-initiated tillers and enhanced senescence in the form of degradation of pigments and proteins. There are instances in wheat [29] and rice [20] where ethylene was found to enhance senescence of the later-initiated tillers and consequently slacken grain filling. In the present study, variation in source activity of the flag leaf between the different classes of tillers of the rice cultivars documented specifically the magnitude of influence of senescence in the control of source activity of the organ. The temporal progress of senescence matched with commensurate decrease in the flag leaf source activity; as a result of which the primary photochemistry as evidenced by $\mathrm{Fv} / \mathrm{Fm}$ ratio declined gradually (Figure 2). This inference was corroborated by the gradual decline in area above the OJIP curve of the tillers (Figure 6). Premature senescence not only reduced the flag leaf area, but also affected the light activated electron transfer in the newly formed tillers (Figure 2). It might have impacted assimilate production for growth as well. Because assimilate transport was not maintained to the later-initiated tillers, they decimated prematurely [4]. In this study, concentration of nitrogen, proteins and chlorophylls of the flag leaf correlated positively with dry weight of panicle (Figure 7) and confirmed the proposition. Because these chemicals determine leaf photosynthesis, senescence induced fall of the materials restricted primary production of the flag leaf. Several observations taken in the past corroborate this inference. Cook and Evans [30] examined 41 lines of Oryza belonging to seven species and found that leaf photosynthetic rate correlated positively with leaf nitrogen content and specific leaf weight across the lines. Ray et al. [31] reported that a delay in leaf senescence increases grain filling, while its promotion works otherwise. In the present study, older tillers were more tolerant to the senescence induced photo-oxidative stress. Hence, temporal reduction in nitrogen, protein and chlorophyll concentrations, primary photo-chemical efficiency and increase of malone-dialdehyde content and peroxidase activity of the flag leaf were less in them compared to younger tillers. We concluded that the gradient in photooxidative stress tolerance between the tillers widens with increase of tiller number and order; the latter-initiated tillers become low productive because of adverse effect of the stress on both source and sink activities.

\section{Acknowledgements}

PKM acknowledges financial support given by Council of Scientific and Industrial Research, New Delhi under the Emeritus Scientist scheme.

\section{REFERENCES}

[1] W. G. Wu, L. T. Wilson and A. M. Mc Clung, "Contribution of Rice Tillers to Dry Matter and Grain Yield," Agronomy Journal, Vol. 90, No. 3, 1998, pp. 317-323. doi:10.2134/agronj1998.00021962009000030001x

[2] K. C. Sahu, E. Kariali and P. K. Mohapatra, "Tiller Dominance in Rice Is Dependent on Assimilate Concentration of the Panicle," Indian Journal of Plant Physiology, Vol. 9, 2004, pp. 402-406.

[3] F. Wang, F. Cheng and G. Zhang, "Difference in Grain Yield and Quality among Tillers in Rice Genotypes Differing in Tillering Capacity," Rice Science, Vol. 14, No. 2, 2007, pp. 135-140. doi:10.1016/S1672-6308(07)60019-5

[4] P. K. Mohapatra and E. Kariali, "Time of Emergence Determines the Pattern of Dominance of Rice Tillers," Australian Journal of Crop Science, Vol. 1, 2008, pp. 5263.

[5] S. Yoshida, "Fundamentals of Rice Crop Science," International Rice Research Institute, Philippines, 1981.

[6] L. J. Luo, Z. K. Li, H. W. Mei, Q. Y. Shu, R. Tabie, D. B. Zhong, C. S. Ying, J. W. Stansel, G. S. Khush and A. H. Pearson, "Overdominant Epistatic Loci Are the Primary Genetic Basis of Inbreeding Depression and Heterosis in Rice. II. Grain Yield Components," Genetics, Vol. 158, 2001, pp. 1755-1771.

[7] L. Zhikang, S. R. M. Pinson, W. D. Park, A. H. Paterson and J. W. Stansel, "Epistasis for Three Grain Yield Components in Rice (Oryza sativa L.)," Genetics, Vol. 145, 1997, pp. 453-465.

[8] S. Peng, G. S. Khush and K. G. Cassman, "Evolution of the New Plant Ideotype for Increased Yield Potential." In: K. G. Cassman, Ed., Breaking the Yield Barrier, International Rice Research Institute, Philippines, 1994, pp. 5-20. 
[9] X. Li, Q. Qian, Z. Fu, Y. Wang, G. Xiong, D. Zeng, X. Wang, X. Liu, S. Teng, F. Hiroshi, M. Yuan, D. Luo, B. Han and J. Li, "Control of Tillering in Rice," Nature, Vol. 422, 2003, pp. 618-621. doi:10.1038/nature01518

[10] D. I. Arnon, "Copper Enzymes in Isolated Chloroplasts. Polyphenoloxidase in Beta vulgaris," Plant Physiology, Vol. 24, No. 1, 1949, pp. 1-15. doi:10.1104/pp.24.1.1

[11] O. H. Lowry, N. J. Rosebrough, A. L. Farr and R. J. Randall, "Protein Measurement with the Folin-Phenol Reagent," Journal of Biological Chemistry, Vol. 193, 1951, pp. 265-275.

[12] R. L. Heath and L. Packer, "Photoperoxidation in Isolated Chloroplasts. I. Kinetics and Stoichiometry of Fatty Acid Peroxidation," Archives of Biochemistry and Biophysics, Vol. 125, No. 1, 1968, pp. 189-198. doi:10.1016/0003-9861(68)90654-1

[13] B. Chance and A. C. Machly, "Assay of Catalase and Peroxidase," Methods in Enzymology, Vol. 2, 1955, pp. 746-775. doi:10.1016/S0076-6879(55)02300-8

[14] T. S. Ma and G. Zuazaga, "Micro-Kjeldahl Determination of Nitrogen. A New Indicator and an Improved Rapid Method," Industrial Engineering Chemistry (Analytical Edition), Vol. 14, No. 3, 1942, pp. 280-282. doi:10.1021/i560103a035

[15] T. Florent, D. S. P. Beatriz, D. R. Marcel and D. Michael, "Leaf Blade Dimensions of Rice (Oryza sativa L. and Oryza glaberrima Steud.), Relationships between Tillers and the Main Stem," Annals of Botany, Vol. 88, No. 3, 2001, pp. 507-511. doi:10.1006/anbo.2001.1447

[16] J. K. Kim and B. S. Vergara, "Morho-Anatomical Characteristics of Different Panicles in High and Low Tillering Rices," Korean Journal of Crop Science, Vol. 36, 1991, pp. 568-575.

[17] M. Dingkuhn and M. Kropff, "Rice," In: E. Zamski and A. A. Schaffer, Eds., Photo-Assimilate Distribution in Plants and Crops: Source and Sink Relationship, Marcel Dekker Inc., New York, 1996, pp. 519-547.

[18] A. K. Biswas and M. A. Choudhuri, "Mechanism of Monocarpic Senescence in Rice," Plant Physiology, Vol. 65, No. 2, 1980, pp. 340-345. doi:10.1104/pp.65.2.340

[19] P. K. Mohapatra, Y. Masamoto, S. Morita, J. Takanashi, T. Kato, T. Itani, J. J. Adu-Gyamfi, M. Shunmugasundaram, N. T. Nguyen and K. Fujita, "Partitioning of ${ }^{13} \mathrm{C}$-Labelled Photosynthate Varies with Growth Stage and Panicle Size in High Yielding Rice," Functional Plant Biology, Vol. 31, No. 2, 2004, pp. 131-139. doi:10.1071/FP03177

[20] E. Kariali and P. K. Mohapatra, "Hormonal Regulation of Tiller Dynamics in Differentially-Tillering Rice Cultivars," Plant Growth Regulation, Vol. 53, No. 3, 2007, pp. 215-223. doi:10.1007/s10725-007-9221-Z
[21] P. K. Mohapatra, B. B. Panda and E. Kariali, "Plasticity of Tiller Dynamics in Wild Rice Oryza rufipogon, Griff.: A Strategy for Resilience in Sub-Optimal Environments," International Journal of Agronomy, Vol. 2011, 2011, Article ID: 543237 . doi:10.1155/2011/543237

[22] S. K. De Datta, "Principles and Practices of Rice Production," Wiley, New York, 1981.

[23] J. Masle, "Competition among Tillers in Winter Wheat: Consequences for Growth and Development of the Crop," In: W. Day and R. K. Atkin, Eds., Proceedings of NATO Advanced Research Workshop on Wheat Growth and Modeling, NATO ASI Series A: Life Sciences, Plenum Press, New York, Vol. 86, 1985, pp. 33-54.

[24] L. T. Evans and S. K. De Datta, "The Relation between Irradiance and Grain Yield of Irrigated Rice in the Tropics, as Influenced by Cultivar, Nitrogen Fertilizer Application and Month of Planting," Field Crops Research, Vol. 2, 1979, pp. 1-17. doi:10.1016/0378-4290(79)90002-9

[25] S. Ciompi, E. Gentili, L. Guidi and G. F. Soldatini, "The Effect of Nitrogen Deficiency on Leaf Gas Exchange and Chlorophyll Fluorescence Parameters in Sunflower," Plant Science, Vol. 118, No. 2, 1996, pp. 177-184. doi:10.1016/0168-9452(96)04442-1

[26] M. J. Paul and C. H. Foyer, "Sink Regulation of Photosynthesis," Journal of Experimental Botany, Vol. 52, No. 360,2001 , pp. $1383-1400$. doi:10.1093/jexbot/52.360.1383

[27] E. D. Smidansky, J. M. Martin, L. C. Hannah, A. M. Fischer and M. J. Giroux, "Seed Yield and Plant Biomass Increases in Rice Are Conferred by Deregulation of Endosperm ADP-Glucose Pyrophosphorylase," Planta, Vol. 216, 2003, pp. 656-664.

[28] J. Beltrano, M. G. Ronco, E. R. Montaldi and A. Carbone, "Senescence of Flag Leaves and Ears of Wheat Hastened by Methyl Jasmonate," Journal of Plant Growth Regulation, Vol. 17, No. 1, 1998, pp. 53-57. doi:10.1007/PL00007012

[29] J. Beltrano, A. Carbone, E. R. Montaldi and J. J. Guiamet, "Ethylene as Promoter of Wheat Grain Maturation and Ear Senescence," Plant Growth Regulation, Vol. 15, No. 2, 1994, pp. 107-112. doi:10.1007/BF00024098

[30] M. G. Cook and L. T. Evans, "Some Physiological Aspects of the Domestication and Improvement of Rice (ORYZA sp.)," Field Crops Research, Vol. 6, 1983, pp. 219-238. doi:10.1016/0378-4290(83)90062-X

[31] S. Ray, W. A. Mondal and M. A. Choudhuri, "Regulation of Leaf Senescence, Grain-Filling and Yield of Rice by Kinetin and Abscisic Acid," Physiologia Plantarum, Vol. 59, No. 3, 1983, pp. 343-346. doi:10.1111/j.1399-3054.1983.tb04212.x 